\title{
Investigação dos Processos de Gelatinização e Extrusão de Amido de Milho
}

\author{
Roberta C. R. Souza e Cristina T. Andrade \\ Instituto de Macromoléculas Professora Eloisa Mano, Universidade Federal do Rio de Janeiro
}

Resumo: Os processos de gelatinização e de extrusão de amido de milho foram estudados. Calorimetria diferencial de varredura e miscroscopia óptica foram utilizadas na determinação da temperatura de gelatinização, $\mathrm{T}(\mathrm{G})$, em função do grau de umidade. Misturado a plastificantes, o amido foi processado em extrusoras monoe dupla-rosca para obtenção de termoplásticos. As propriedades mecânicas dos filmes obtidos por processamento em extrusora dupla-rosca foram investigadas. A análise termo-dinâmico-mecânica do filme de amido termoplástico com $33 \%(\mathrm{p} / \mathrm{p})$ de plastificantes revela a presença de duas transições distintas, atribuídas às transições das duas macromoléculas constituintes do amido.

Palavras-chave: Gelatinização, amidos termoplásticos, extrusão, propriedades físicas.

\section{Investigation of corn starch gelatinization and extrusion processes}

\begin{abstract}
The gelatinization and extrusion processes of corn starch were studied. Differential scanning calorimetry and optical microscopy were used to determine the gelatinization temperature, as a function of the water content. Plasticized corn starch was processed in single- and twin-screw extruders to produce thermoplastic materials. The mechanical properties of the films obtained in the twin-screw extruder were evaluated. The thermo-dynamical-mechanical analysis of the thermoplastic starch with $33 \%(\mathrm{w} / \mathrm{w})$ plasticizers showed two transitions, attributed to the starch constituents.
\end{abstract}

Keywords: Gelatinization, thermoplastic starch, extrusion, physical properties.

\section{Introdução}

Os artefatos plásticos convencionais produzidos a partir de polímeros sintéticos são inertes ao ataque imediato de microorganismos. Embora esta propriedade faça com que esses materiais apresentem um tempo longo de vida útil, por outro lado, ocasionam sérios problemas ambientais após o seu descarte, devido ao grande tempo necessário para a sua degradação ${ }^{[1,2]}$. A adição de um substrato biodegradável a uma matriz polimérica sintética induz a digestão de tal aditivo por microorganismos, o que favorece o esfarelamento da matriz polimérica sintética ${ }^{[3]}$. A introdução de amido a matrizes poliméricas sintéticas, realizada inicialmente em meados dos anos 70 , tem-se mostrado uma alternativa viável para a obtenção de plásticos mais facilmente biodegradáveis ${ }^{[4]}$.

Atualmente, há o interesse no desenvolvimento de materiais termoplásticos compostos essencialmente de amido ${ }^{[5,6]}$. O conhecimento de algumas propriedades características do amido e de seu comportamento durante o processamento têm-se mostrado de muita importância para o desenvolvimento de amidos termoplásticos ${ }^{[7-10]}$. Ao contrário dos polímeros sintéticos, o amido é obtido a partir de fontes renováveis, sendo biossintetizado e estocado pelas plantas na forma de grânulos de tamanhos variáveis, que dependem da fonte ${ }^{[4]}$. O amido é constituído de duas macromoléculas principais: a amilopectina, que é uma molécula ramificada, e a amilose, que é uma molécula essencialmente linear. Ambas possuem massa molar elevada ${ }^{[11-13]}$.

Os grânulos de amido apresentam birrefringência quando observados em microscópio óptico sob luz polarizada, o que indica um certo grau de organização molecular. A parte linear das moléculas de amilopectina forma estruturas helicoidais duplas, estabilizadas por pontes de hidrogênio entre grupamentos hidroxila. São

Autor para correspondência: Roberta C. R. Souza, UFRJ/IMA, C. P. 68525, CEP: 21945-970, Rio de Janeiro, RJ, E-mail: roberta@ima.ufrj.br. 
elas que dão origem às regiões cristalinas dos grânulos. A região amorfa é composta pelas cadeias de amilose e pelas ramificações da amilopectina ${ }^{[14,15]}$. Alguns fenômenos afetam as propriedades dos amidos. Um deles é a gelatinização, o processo de transformação do amido granular em pasta viscoelástica ${ }^{[16-18]}$. Durante o aquecimento de dispersões de amido em presença de excesso de água, inicialmente ocorre o inchamento de seus grânulos até temperaturas nas quais ocorre o rompimento dos grânulos, com destruição da ordem molecular e mudanças irreversíveis nas suas propriedades. A temperatura na qual ocorre este tipo de transformação é chamada de temperatura de gelatinização, $T(G)^{[17,19]}$. Por outro lado, quando o amido é aquecido em presença de pequenas quantidades de água, o fenômeno que indica o rompimento de seus grânulos é conhecido como fusão ${ }^{[20]}$.

Para obtenção de um termoplástico à base de amido, sua estrutura granular precisa ser destruída para dar origem a uma matriz polimérica homogênea e essencialmente amorfa. Este trabalho teve como objetivo a determinação do tipo de processamento mais adequado para a obtenção de um termoplástico à base de amido. Para isto, as amostras de amido e de plastificantes foram processadas por extrusão. A caracterização dos filmes obtidos foi feita através de observações visuais, microscopia eletrônica de varredura e através de suas propriedades mecânicas. A determinação da temperatura ótima para o processamento baseou-se em informações obtidas por calorimetria diferencial de varredura e nas observações por microscopia óptica, as quais possibilitaram determinar a temperatura na qual ocorre o rompimento dos grânulos, em presença de teores variados de plastificantes.

\section{Experimental}

\section{Materiais}

O amido de milho foi produzido pela Refinações de Milho Brasil Ltda., e possui grau alimentício; o glicerol foi fabricado pela Vetec Química Fina Ltda. e foi utilizado como recebido.

\section{Purificação por lavagem}

$\mathrm{O}$ amido de milho foi disperso em excesso de água destilada e deionizada e esta dispersão foi agitada vigorosamente por cerca de 4 horas. A dispersão foi filtrada e o material retido foi seco em estufa até massa constante ( 40 horas). O produto obtido foi triturado e armazenado sob condições ambientes.

\section{Teor em cinzas}

Massas iguais de amido de milho comercial e de amido lavado foram pesadas em triplicata em cadinhos de porcelana e inicialmente incineradas em chama oxidante. Após este tratamento, permaneceram a $550^{\circ} \mathrm{C}$ por um período de 24 horas em mufla. As amostras foram posteriormente resfriadas em ambiente seco e pesadas para a determinação do teor em cinzas.

\section{Determinação da temperatura de gelatinização, $T(G)$}

$\mathrm{O}$ amido de milho foi espalhado sobre lâmina de vidro. Gotas de água foram adicionadas de modo a obter-se uma dispersão a $5 \mathrm{~g} / \mathrm{l}$. A dispersão foi então analisada em Microscópio Óptico Olympus BX50, a diferentes temperaturas. A temperatura foi variada de 25 a $90^{\circ} \mathrm{C}$, por meio de placa de aquecimento Linkan THM5600.

\section{Determinação da $T(G)$ em função do grau de umidade}

Ensaios de calorimetria diferencial de varredura foram realizados em equipamento Perkin Elmer DSC-7, para a determinação da temperatura de transição relacionada ao rompimento dos grânulos, em função do grau de umidade. As amostras foram analisadas sob taxa de aquecimento de $10^{\circ} \mathrm{C} / \mathrm{min}$, na faixa 30 a $270^{\circ} \mathrm{C}$. Para todos os ensaios, utilizou-se um porta-amostras de aço inoxidável vedado e, como referência, um porta-amostras vazio.

\section{Processamento em extrusora mono-rosca}

Cerca de $9 \%$ de água $(35,5 \mathrm{~g})$ e $15 \%$ de glicerol $(59,2 \mathrm{~g})$ foram misturados a $300 \mathrm{~g}$ de amido previamente lavado e seco. Essa pré-mistura foi processada em extrusora mono-rosca Plasti-Corder Brabender modelo GNF 106/2, equipada com quatro zonas de aquecimento, cujas temperaturas foram mantidas a $70,80,95$ e $115^{\circ} \mathrm{C}$, da zona de alimentação à saída da matriz. A rotação da rosca variou entre 20 e 40 rpm. Para a obtenção dos filmes, as amostras extrusadas foram imediatamente prensadas a $110^{\circ} \mathrm{C}$ e $92 \mathrm{kPa}$, por um período de $15 \mathrm{~min}$.

\section{Processamento em extrusora dupla-rosca}


Cerca de $300 \mathrm{~g}$ de amido foram misturados a $18 \%$ de água $(80,6 \mathrm{~g})$ e a $15 \%(67,2 \mathrm{~g})$ de glicerol, e processadas em extrusora dupla-rosca, acoplada ao equipamento Haake Rheocord 90 System. A extrusora foi alimentada de forma contínua e as temperaturas das quatro zonas de aquecimento foram mantidas a 90$100,110-120,120-130$ e $90^{\circ} \mathrm{C}$. O material foi obtido sob forma de fita, com auxílio de uma matriz de dimensões $25 \mathrm{~mm}$ x $1 \mathrm{~mm}$, acoplada à saída da extrusora. O material termoplástico passou por uma calandra à medida em que saía da extrusora, o que permitiu a uniformização e o resfriamento dos filmes. As superfícies desses filmes, assim como a superfície dos filmes obtidos por processamento em extrusora mono-rosca, foram avaliadas por microscopia óptica, em Microscópio Estéreo Olimpus SZH10.

\section{Microscopia eletrônica de varredura}

Grânulos de amido e amostras do termoplástico obtido por processamento em extrusora dupla-rosca foram observados através de microscopia eletrônica de varredura em equipamento Jeol JSM5300. Os grânulos de amido foram espalhados sobre um suporte e recobertos com uma camada fina de ouro. Os experimentos foram realizados sob voltagem de $5 \mathrm{kV}$. As amostras de termoplástico foram analisadas após secagem, fraturamento em $\mathrm{N}_{2}$ líquido e recobrimento com ouro. As superfícies fraturadas e as superfícies extrusadas foram analisadas a $20 \mathrm{kV}$.

\section{Propriedades mecânicas do amido termoplástico}

Amostras de filmes de amido termoplástico obtidas por processamento em extrusora dupla-rosca foram con-

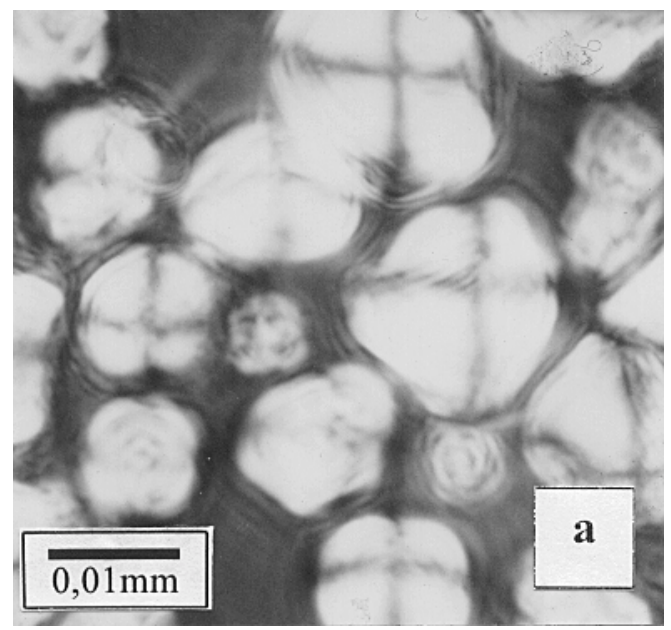

dicionadas a diferentes umidades relativas do ar, de modo a apresentarem teores de umidade de 8,12 e $18 \%$. As amostras condicionadas foram analisadas através de ensaios de tração em Máquina Universal de Ensaios Instron 4204, equipada com garras pneumáticas, sob velocidade de $5 \mathrm{~mm} / \mathrm{min}$. Foram analisados um mínimo de 5 corpos de prova para cada uma das amostras, cortadas de acordo com a Norma ASTM 882-75b, com dimensões de $10 \mathrm{~cm}$ de comprimento por $8 \mathrm{~mm}$ de largura.

\section{Análise termo-dinâmico-mecânica, DMTA.}

As amostras obtidas por processamento em extrusora dupla-rosca foram prensadas em camadas em prensa Carver a $120^{\circ} \mathrm{C}$ e $62 \mathrm{kPa}$, por $10 \mathrm{~min}$. As amostras prensadas foram cortadas nas dimensões $2,5 \mathrm{~cm} \mathrm{x} 1 \mathrm{~cm} \mathrm{e}$ espessura de $3 \mathrm{~mm}$, e condicionadas a $18 \%$ de umidade. $\mathrm{O}$ analisador termo-dinâmico-mecânica modelo MkIII da Rheometric Scientific foi utilizado. As amostras foram submetidas a uma deformação senoidal de $10 \%$ no modo de flexão, no intervalo de temperatura de $-80 \mathrm{a}$ $150^{\circ} \mathrm{C}$, a uma taxa de aquecimento de $2^{\circ} \mathrm{C} / \mathrm{min}$.

\section{Resultados e Discussão}

A lavagem do amido visou a eliminação de impurezas solúveis em água. Após a lavagem, o amido de milho mostrou-se com uma coloração mais clara do que a do amido comercial. Os teores em cinzas encontrados para as amostras de amido lavado e comercial foram respectivamente de $0,10 \mathrm{e}$ $0,14 \%$, o que mostra que o teor de material inorgânico em ambos é baixo, e que o processo de lavagem do amido foi eficiente para a eliminação

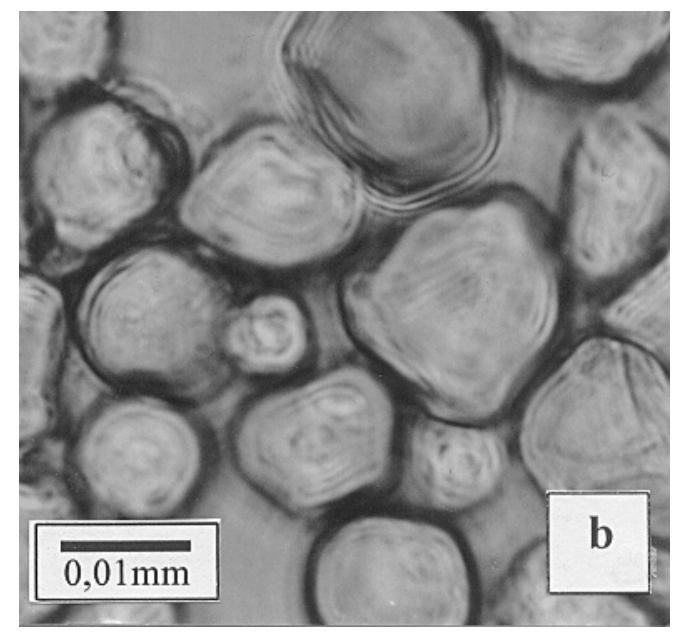

Figura 1: Micrografias das dispersões de amido a $5 \mathrm{~g} / 1$ e $25^{\circ} \mathrm{C}$; a) e b) aumento de 100 vezes sob luz polarizada e natural, respectivamente. 

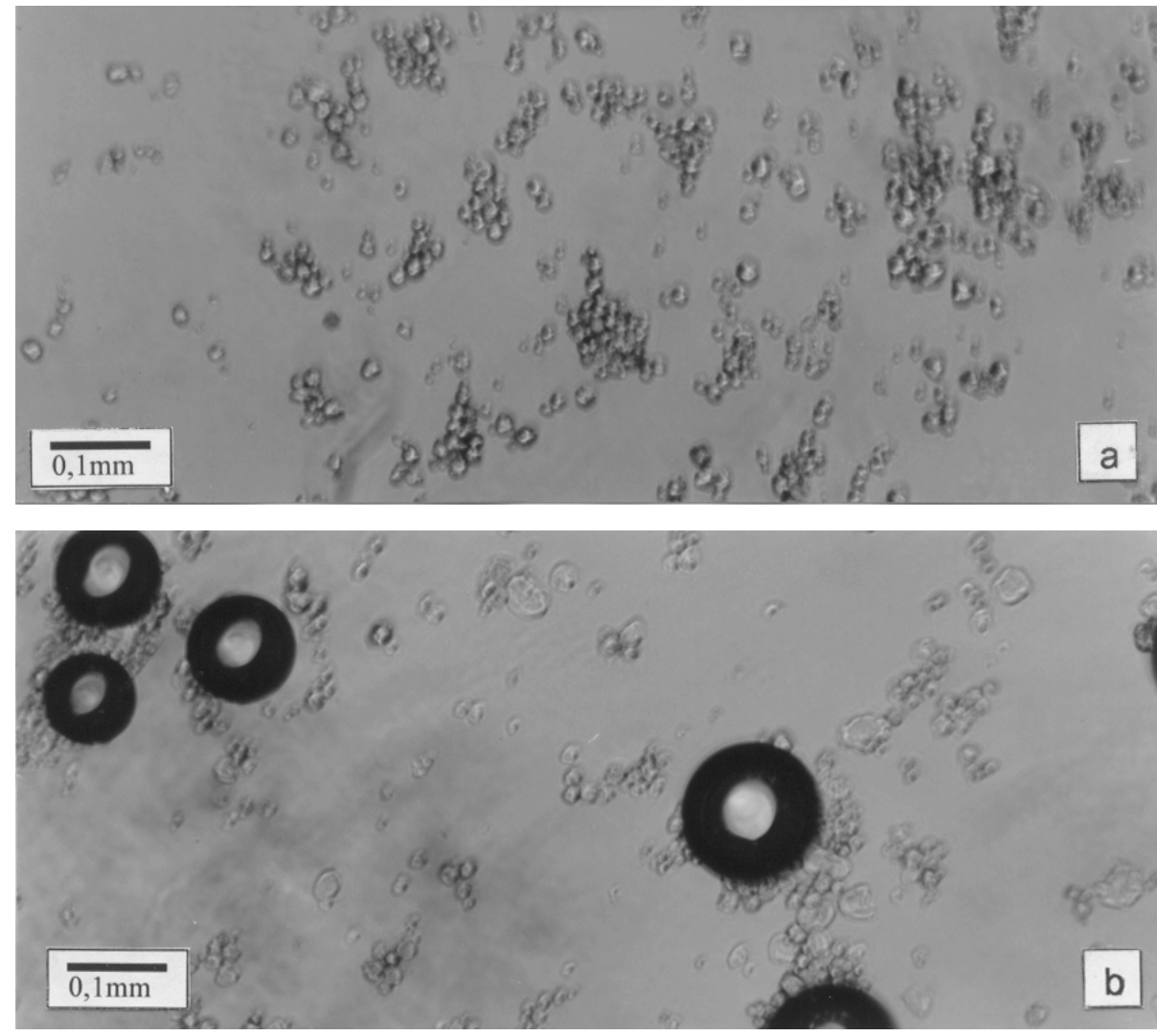

Figura 2: Micrografias de dispersões de amido a $5 \mathrm{~g} / 1$ e aumento de 10 vezes, a) $40^{\circ} \mathrm{C}$ e b) $60^{\circ} \mathrm{C}$.

de parte do material inorgânico presente na amostra de amido comercial.

$\mathrm{O}$ aquecimento de dispersões aquosas de amido de milho, sob observação contínua, permitiu a determinação da temperatura de gelatinização, além da visualização do comportamento dos grânulos durante o processo. A Figura 1 mostra a micrografia da dispersão de amido a $25^{\circ} \mathrm{C}$ com aumento de 100 vezes, com luz natural e luz polarizada. Observa-se sob luz polarizada a presença da cruz de Nicols, que evidencia a semicristalinidade dos grânulos.

As micrografias da Figura 2 mostram as dispersões de amido a 40 e $60^{\circ} \mathrm{C}$. Observa-se que o aumento da temperatura de $40 \mathrm{a} 60^{\circ} \mathrm{C}$ provoca uma maior absorção de água pelos grânulos, que se tornam mais inchados.

A $70^{\circ} \mathrm{C}$, os grânulos de amido tornam-se excessivamente inchados; cerca de $70 \%$ dos grânulos são rompidos (Figura 3a). Esta temperatura pode ser considerada como a temperatura de gelatinização do amido de milho. A temperaturas superiores a $75^{\circ} \mathrm{C}$, a observação deste material sob luz polarizada mostra a ausência de birrefringência (Figura 3b), resultante da perda da ordenação molecular previamente existente.

Tendo-se em vista que o teor de água presente nas dispersões de amido afeta o processo de rompimento dos grânulos, a determinação da temperatura na qual esta transição ocorre, em função do grau de umidade, faz-se necessária. A Tabela 1 apresenta as temperaturas de transição observadas para amostras de amido com grau de umidade entre 0 e $60 \%$. Os resultados mostram que a transição térmica relacionada à fusão ocorreu a temperatura bem superior às observadas para os grânulos de amido em presença de teores de água acima de $10 \%$.

O processamento de pré-misturas amido-plas-

Tabela 1: Grau de umidade e temperatura do máximo, $\mathrm{T}_{\text {máx }}$, das endotermas obtidas por DSC para amostras de amido de milho.

\begin{tabular}{cc}
\hline Teor de água $(\%)$ & Tmáx $\left({ }^{\circ} \mathbf{C}\right)$ \\
\hline 0 & 168 \\
10 & 126 \\
20 & 123 \\
30 & 120 \\
40 & 109 \\
50 & 108 \\
60 & 72 \\
\hline
\end{tabular}



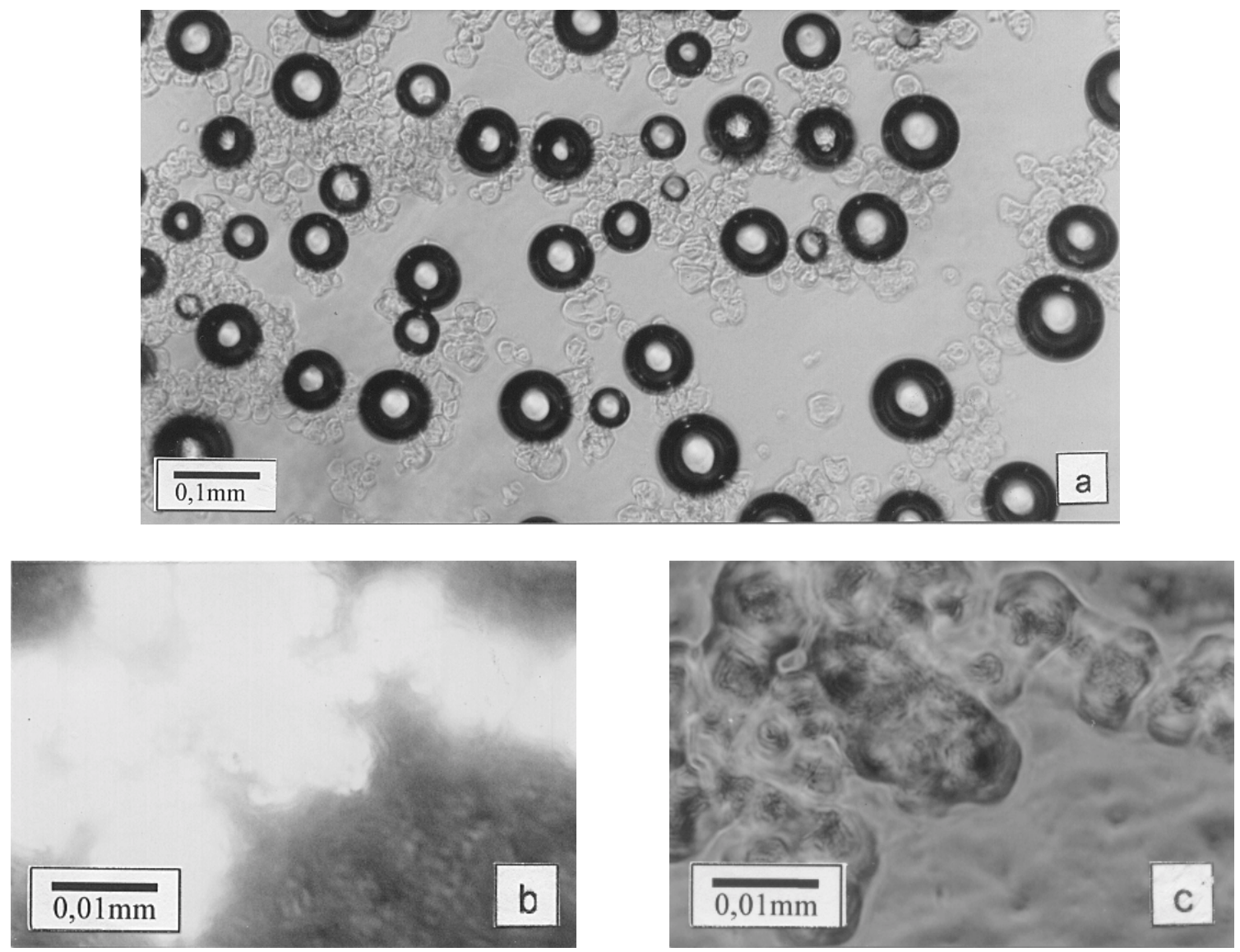

Figura 3: Micrografias de dispersões de amido a $5 \mathrm{~g} / 1$, a $75^{\circ} \mathrm{C}$; a) aumento de 10 vezes; b) e c) aumento de 100 vezes com luz polarizada e natural, respectivamente.

tificantes em extrusora mono-rosca promoveu a obtenção de um perfil aparentemente homogêneo. Entretanto, a observação do filme através de microscopia óptica, com aumento de 5 vezes, mostra a presença de grumos, o que sugere que, nas condições utilizadas, nem todos os grânulos de amido foram rompidos durante o processamento (Figura 4).

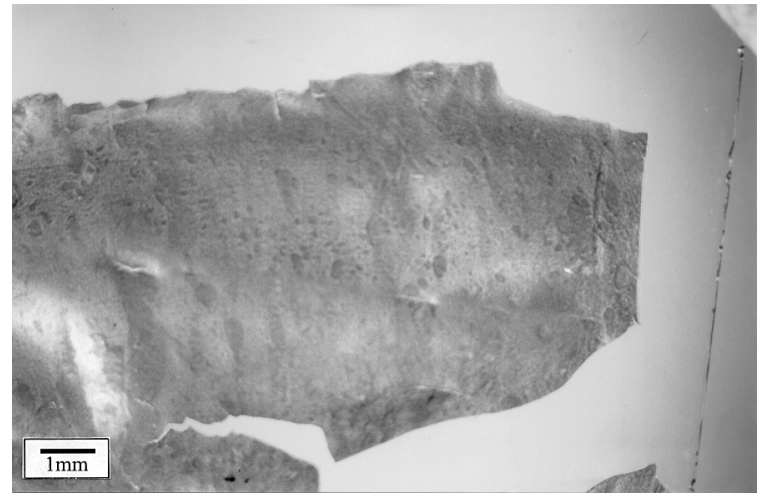

Figura 4: Micrografia do termoplástico obtido por processamento em extrusora mono-rosca.
A utilização da extrusora dupla-rosca provoca um maior cisalhamento da pré-mistura amidoplastificantes e, como resultado, os filmes obtidos mostraram-se completamente homogêneos, sem a presença dos grumos verificados nos filmes obtidos por processamento em extrusora mono-rosca. O filme mostrado na micrografia da Figura 5 revela que

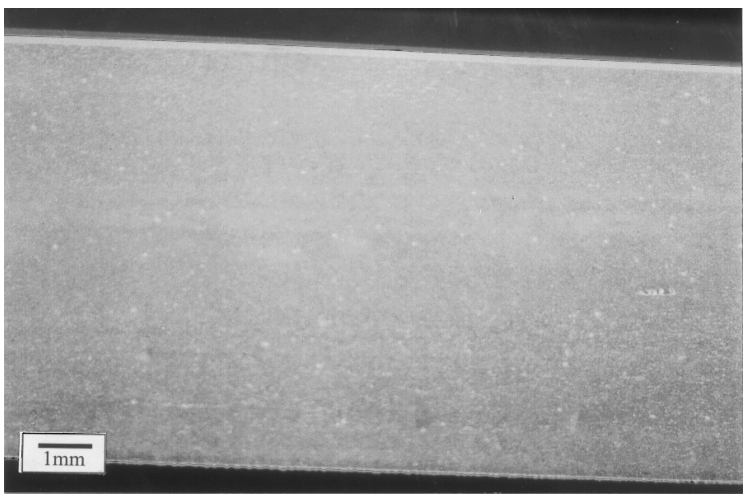

Figura 5: Micrografia do termoplástico obtido por processamento em extrusora dupla-rosca. 


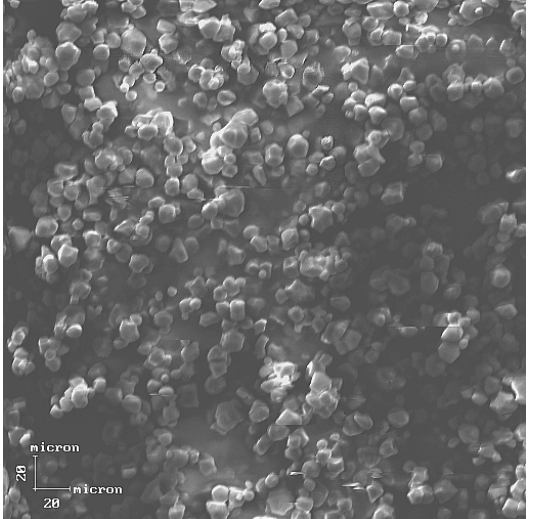

(a)

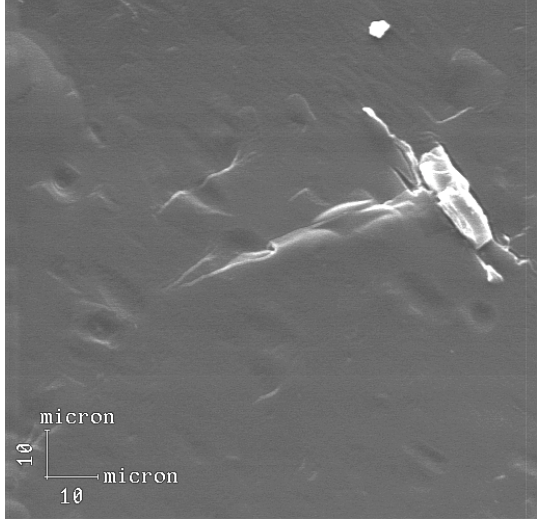

(b)

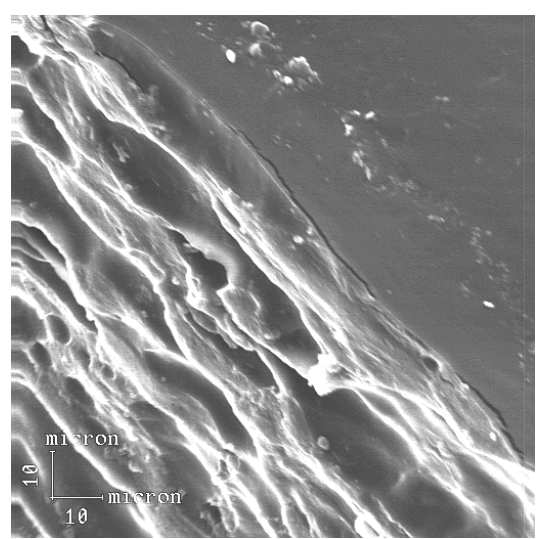

(c)

Figura 6: Microscopia eletrônica de varredura; a) grânulos de amido de milho, b) superfície fraturada, c) superfície extrusada do amido termoplástico.

o cisalhamento provocado pela extrusora dupla-rosca foi capaz de promover o rompimento dos grânulos de amido, dando origem a uma matriz polimérica homogênea.

Durante o processamento em extrusora duplarosca, observou-se que o torque desenvolvido ficou na faixa de $20 \mathrm{Nm}$, quando a rotação dos parafusos foi mantida em $40 \mathrm{rpm}$. Torque tão elevado era esperado, tendo-se em vista que o rompimento dos grânulos de amido em presença de pequena quantidade de água é dificultado e necessita maior energia para ser realizado. $\mathrm{O}$ aumento da velocidade de rotação dos parafusos para $50 \mathrm{rpm}$ ocasionou a queda do torque desenvolvido para $10 \mathrm{Nm}$, o que também é razoável, visto que o cisalhamento maior favorece o processamento. Os grânulos observados na micrografia da Figura 6a apresentam diâmetros entre 5 e $20 \mu \mathrm{m}$ e formatos que variam de arredondados a poligonais. A análise foi realizada sob voltagem de $5 \mathrm{kV}$; a aplicação de voltagens superiores acarreta a degradação do material. A superfície obtida após a fratura do termoplástico processado em extrusora dupla-rosca e a superfície extrusada foram observadas e são mostradas nas Figuras $6 b$ e $6 c$, respectivamente. Nas superfícies observadas, raros são os grânulos de amido, o que indica que o processamento em extrusora dupla-rosca levou à obtenção de uma matriz polimérica bastante homogênea.

A Figura 7 mostra o gráfico de tensão-deformação para as amostras de amido termoplástico com graus de umidade diferentes. As propriedades mecânicas do amido termoplástico são altamente influenciadas pelo teor de água presente nos filmes e revelam o efeito plastificante exercido pela água. O material com $8 \%$ de água apresentou o maior valor de tensão na ruptura e baixo alongamento, o que caracteriza um material termoplástico rígido e quebradiço. O material com $18 \%$ de água necessitou de menor tensão para a sua ruptura e sofreu o maior alongamento.

A resposta viscoelástica do material termoplástico pode ser avaliada através de sua análise termo-mecânico-dinâmica (DMA), submetendo-se a amostra a deformações angulares. A análise de DMA dos termoplásticos obtidos por processamento em extrusora dupla-rosca revelam o aparecimento de duas transições em regiões distintas, como é mostrado no termograma da Figura 8. Tendo-se em vista que o termoplástico obtido mostrou-se bastante

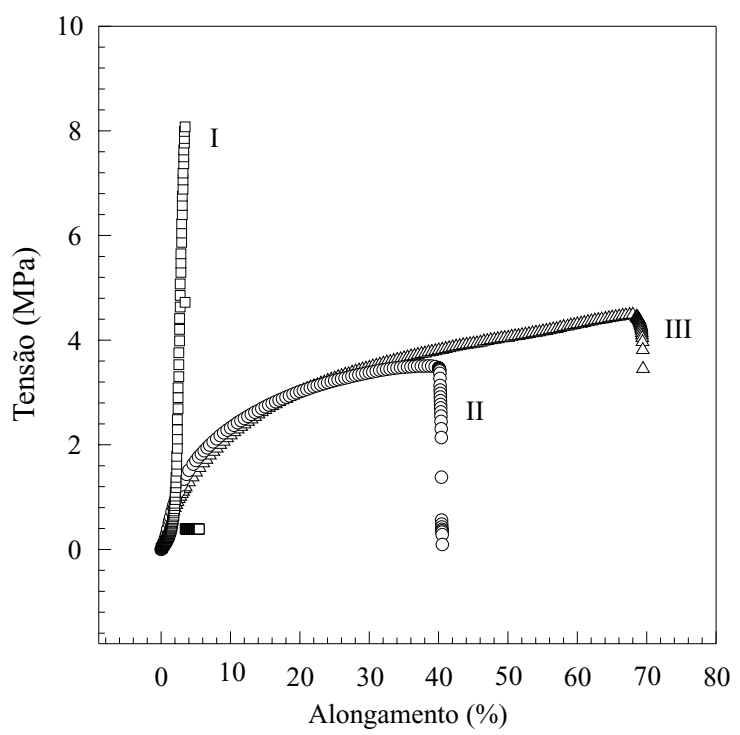

Figura 7 - Tensão versus deformação para amidos termoplásticos com graus de umidade diferentes; I $(\boldsymbol{\square}) 8 \%$, II $(\triangle) 12 \%$ e III $(O) 18 \%$. 


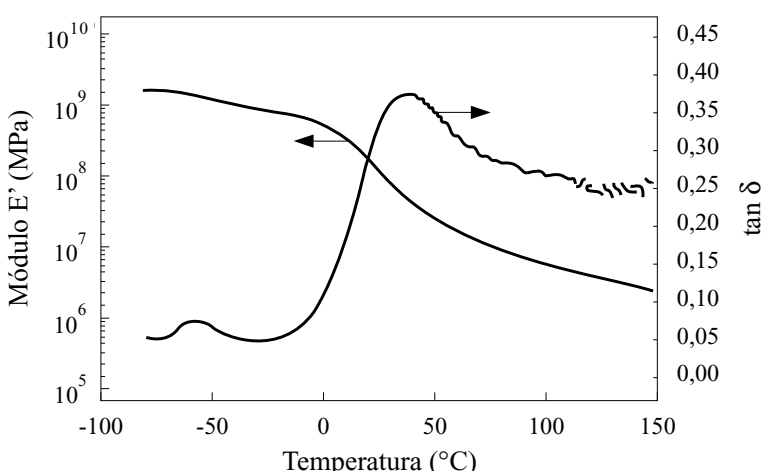

Figura 8 - Termograma obtido por análise termo-mecânico-dinâmica para o termoplástico de amido processado em extrusora dupla-rosca; E', módulo de armazenamento; $\tan \delta$, amortecimento.

homogêneo e transparente, pode-se afirmar que o material é essencialmente amorfo. A macromolécula de amilopectina, por possuir um grande número de ramificações e por apresentar, em geral, uma massa molar maior do que a da amilose, provavelmente possui uma mobilidade bem mais restrita do que a da molécula de amilose ${ }^{[7,8]}$. Desta forma, sugere-se que a primeira transição $\left(-55^{\circ} \mathrm{C}\right)$ esteja relacionada ao movimento das cadeias de amilose, e que a segunda transição $\left(45^{\circ} \mathrm{C}\right)$ esteja relacionada ao movimento das cadeias de amilopectina.

\section{Conclusões}

O estudo do processo de gelatinização do amido de milho indica que os grânulos de amido sofrem inchamento e se rompem mais facilmente quando em presença de teores de água superiores a $40 \%$, e que há necessidade de aplicação de temperaturas mais elevadas quando o teor de água é mais baixo. O processamento em extrusora mono-rosca, nas condições utilizadas, não favoreceu o rompimento de todos os grânulos de amido. Os materiais termoplásticos à base de amido e de plastificantes, obtidos por processamento em extrusora dupla-rosca, mostraram-se bastante flexíveis e transparentes, o que indica que a estrutura supramolecular dos grânulos foi destruída durante o processamento. A técnica de microscopia eletrônica de varredura permitiu a confirmação desta hipótese. Os filmes de amido termoplástico obtidos por processamento em extrusora dupla-rosca mostraram-se adequados para avaliação de suas propriedades físicas.

\section{Agradecimentos}

As autoras agradecem à CAPES e ao CNPq.

\section{Referências Bibliográficas}

1. Vaydia, U.R.; Bhattacharya, M. \& Zhang, D. - Polymer, 36, p.1179 (1995).

2. Huang, J.C.; Shetty A.S. \& Wang M.S. - Adv. Polym. Technol., 10, p.23 (1990).

3. Santos, T. - Plástico Moderno, p.24, Jul. (1990).

4. Reis, R.L.; Cunha, A.M.; Allan, P.S. \& Bevis, M.J. Adv. Polym. Technol., 16, p.263 (1997).

5. Soest, J. J. G.; Hulleman, S. H. D., Wit, D. \& Vliegenthart, J. F. G. - Carbohydr. Polym., 29, p. 225 (1996).

6. Pellegrini, C. \& Tomka, I. - Macromol. Symp. 127, p.31 (1998).

7. Arévalo-Niño, K.; Sandoval, C.F.; Galan, L.J.; Iman, S.H.; Gordon, S.H. \& Greene, R.V. - Biodegradation, 7, p.231 (1996).

8. Govindasamy, S.; Campanella, O.H. \& Oates, C.G. Carbohydr. Polym., 30, p.275 (1996).

9. Onteniente, J.P.; Etienne, F.; Bureau, G. \& Claude, J. Starch, 48, p.10 (1996).

10. Willet, J.L.; Millard, M.M. \& Jasberg, B.K. - Polymer, 38, p. 5983 (1997).

11. Curá, J.A.; Jansson, P.E. \& Krisman C.R. - Starch, 47, p. 207 (1995).

12. Carioca, J.O.B.; Arora, H.L.; Selvan, P.V.P.; Tavares, F.C.A.; Kennedy, J.F. \& Knill, C.J. - Starch, 48, p.322 (1996).

13. Nilsson, G.S.; Bergquist, K.E., Nilsson, U \& Gorton, L. - Starch, 48, p.352 (1996).

14. Soest J. J. G.; Hulleman, S. H. D., Wit, D. \& Vliegenthart, J.F.G - Ind. Crop Prod., 5, p.11 (1996).

15. Keetels, C.J.A.M.; Oostergetel, G.T. \& Vliet, T. Carbohydr. Polym., 30, p.61 (1996).

16. Jang, J.K. \& Pyun, Y.R. - Starch, 48, p.48 (1996).

17. Ragheb, A.A.; El-Thalouth, I.A. \& Tawfik, S. - Starch, 48, p.57 (1996).

18. Beleia, A.; Miller R.A. \& Hoseney, R.C. - Starch, 48, p.259 (1996).

19. Thiewes, H.J. \& Steeneken, A.M. - Carbohydr. Polym., 32, p.123 (1997).

20. Farhat, I.A. \& Blanshard, J.M.V. - Carbohydr. Polym., 34, p.263 (1997).

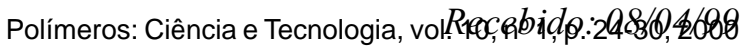
Aprovado: 30/11/99 